\title{
Heritability of Electronically Recorded Daily Body Weight and Correlations with Yield, Dry Matter Intake, and Body Condition Score
}

\author{
J. K. Toshniwal, ${ }^{\star}$ C. D. Dechow, ${ }^{\star 1}$ B. G. Cassell, † J. A. D. R. N. Appuhamy,† and G. A. Varga* \\ *Department of Dairy and Animal Science, Pennsylvania State University, University Park 16802 \\ †Department of Dairy Science, Virginia Polytechnic Institute and State University, Blacksburg 24061
}

\section{ABSTRACT}

The objectives of this study were to estimate heritability for daily body weight (BW) and genetic correlations of daily BW with daily milk yield (MY), body condition score (BCS), dry matter intake, fat yield, and protein yield. The Afiweigh cow body weighing system records BW of every cow exiting the milking parlor. The Afiweigh system was installed at the Pennsylvania State University dairy herd in August 2001 and in July 2004 at the Virginia Tech dairy herd. The edited data included 202,143 daily BW and 290,930 daily MY observations from 575 Pennsylvania State University and 120 Virginia Tech Holstein cows. Data were initially analyzed with a series of 4-trait animal models, followed by random regression models. The models included fixed effects for age within lactation group, week of lactation, and herd-date. Random effects included animal, permanent environment, and error. The order of the polynomials for random animal and permanent environmental effects with the random regression model for daily BW was 4 and 6 , respectively. Heritability estimates for daily $\mathrm{BW}$ ranged from 0.48 to 0.57 and were largest between 200 and 230 and smallest at $305 \mathrm{~d}$ of lactation. Genetic correlations were large between BW and BCS (0.60). The genetic correlation between daily BW and MY was -0.14 but was positive (0.24) after adjusting for BCS. Electronically recorded daily $\mathrm{BW}$ is highly heritable, and genetic evaluations of daily BW and BW change across the lactation could be used to select for less early lactation BW loss.

Key words: body weight, heritability, genetic correlation

\section{INTRODUCTION}

Genetic selection for milk production has led to increases in DMI but also has resulted in more negative

Received August 19, 2007.

Accepted April 28, 2008.

${ }^{1}$ Corresponding author: cdd1@psu.edu energy balance (NEB) and more body tissue mobilization during early lactation. Genetic correlations between milk yield (MY) and DMI (0.28) indicate that the correlated response in DMI from selection on yield alone cannot meet the extra requirements for increased milk production (Veerkamp et al., 2000). This is supported by genetic correlations of -0.70 between yield and measures of energy balance (Svendsen et al., 1994 ) and -0.67 to -0.37 between yield and BW gain (Lee et al., 1992; Jensen et al., 1995).

The extent and duration of NEB strongly influences fertility in dairy cattle (Butler et al., 1981; Butler and Smith, 1989). Genetic evaluations of energy balance directly would require feed intake data on a large population, which is time-consuming and costly to collect. Coffey et al. (2001) demonstrated that energy balance may be estimated in part from change in BW and BCS. Change in daughter BW and BCS can be used to help create overall energy balance curves for sires.

The contribution of body energy to milk production (partly indicated by loss in BW) is thought to have a negative effect on dairy cows, thus leading to poorer health and fertility. Berry et al. (2003) demonstrated that selection for greater BCS resulted in less negative effects on fertility when simultaneously selecting for greater milk production. Veerkamp et al. (2000) reported a negative genetic correlation between energy balance and days to initiation of luteal activity after calving (-0.60). Unfavorable body energy status might also lead to elevated SCC and mastitis incidence, thereby compromising udder health (Banos et al., 2006). In fact, a significant genetic correlation was reported $(-0.16)$ between $\mathrm{BCS}$ and clinical mastitis (Lassen et al., 2003).

Body weight is a moderate to highly heritable trait and may be useful to select for more efficient cows with less NEB in early lactation (Veerkamp et al., 2000). Most heritability estimates for BW are based on data from single experimental herds during limited lactation periods (van Elzakker and van Arendonk, 1993; 
Veerkamp and Brotherstone, 1997). Alternatively, equations have been developed to use type traits that are usually measured at a single time point to predict live weight in dairy cows for genetic evaluations (Koenen and Groen, 1998; Coffey et al., 2003). However, BW measurement can now be automated (Peiper et al., 1993; Maltz, 1997), which could provide daily BW estimates for implementation in progeny-testing programs. The objectives of this study were to estimate the heritability of daily BW across lactation and genetic correlations of daily BW with daily MY, DMI, BCS, fat yield (FY), and protein yield (PY).

\section{MATERIALS AND METHODS}

\section{Data}

Collected data included records of daily BW, daily MY, DMI, BCS, test-day FY, and test-day PY. Body weight and MY records were collected from 530 (1,056 lactation records) and 120 (193 lactation records) Holstein cows from the Pennsylvania State University (PSU) and Virginia Tech (VT) dairy herds, respectively. Data on DMI were recovered from a variety of nutritional studies at PSU (Ordway et al., 2002; Chung et al., 2005; Karcher et al., 2007), where feed and refusals were weighed daily for cows housed in a tie-stall barn. The studies focused on nutritional treatments applied during the transition period, so DMI were recorded between -28 DIM and 59 DIM in those studies. Body condition score was recorded on a scale of 1 (emaciated) to 5 (obese) with 0.1 increments on 4 different occasions at PSU: calving, 30 DIM, first breeding, and dry-off. Body condition scores at calving and other time points are not the same trait genetically but have high genetic correlations (Dechow et al., 2004), so were considered the same trait in this study due to a limited number of observations. Fat yield and PY were obtained on a monthly basis from Dairy Herd Improvement Association testing for PSU. Daily BW and MY were retrieved from AfiFarm herd management software (S. A. E. Afikim, Kibbutz Afikim, Israel). Daily BW was from the Afiweigh cow body weighing system, which records the weight of every cow exiting the milking parlor. Body weights from the morning and evening milking are averaged and stored as a single value by AfiFarm at PSU, whereas both morning and evening BW are retained in the VT herd. Morning and evening BW were averaged for VT to be consistent with PSU. Afiweigh was installed at PSU in August 2001 and in July 2004 at VT. The data were collected from the date of installation through December 2005 in both herds.

\section{Edits}

The initial number of daily BW records from the PSU and VT herds and the number of records eliminated for each edit are reported in Table 1. Body weight was not captured due to scale malfunction or failure to read the transponder of the cow as they walked across the scale for $26 \%$ of eligible days in the PSU herd, and for fewer than $2 \%$ in the VT herd. The discrepancy between the herds likely reflects newer equipment in the VT herd and the electronic storage of BW twice daily for VT. Because daily BW at PSU is stored as the average of morning and evening $\mathrm{BW}$, a missing value at either time frame results in a missing BW for the day, whereas either morning or evening BW was used as daily BW if one value was missing for VT. Body weight and MY recorded after 365 DIM were eliminated. To eliminate recording errors due to a cow running across the scale, more than 1 animal climbing the scale at 1 time, or any other aberrant records, outliers were detected by generating a predicted BW and MY curve with a regression model using fifthorder polynomials for DIM nested within cow and lactation using the MIXED procedure of SAS (SAS Institute, 2000). Body weight and MY were removed if either BW or MY was more than 4 standard deviations from the predicted curve on that day. Visual inspection of BW curves from PSU indicated that some cows had an identical BW for several consecutive weeks because of software or scale errors. Therefore, daily BW records that were identical for more than $5 \mathrm{~d}$ for the same cows were eliminated. No VT records were eliminated with this edit. Additional edits specific to the PSU herd were the removal of records from 15-mo-old heifers that had been induced into lactation (Kensinger et al., 2005) and removal of all records from July 14 through November 27, 2003, because of scale malfunction on 1 side of the PSU milking parlor. Records were not removed for any cow with clinical disease incidence, because one of the primary interests in daily BW as a selection tool would be to select for cows less subject to disease.

\section{Statistical Models}

Data were analyzed with a series of 4-trait animal models to estimate heritability and correlations among daily BW, daily MY, FY, PY, DMI, and BCS in ASREML (Gilmour et al., 2006) using the following model:

$$
\boldsymbol{y}=X \boldsymbol{\beta}+Z \boldsymbol{a}+W \boldsymbol{p}+\boldsymbol{e}
$$


Table 1. Number of potential daily BW records and the number of daily BW eliminated for successive edits in the Pennsylvania State University (PSU) and Virginia Tech (VT) dairy herds

\begin{tabular}{lrr}
\hline Item & PSU & VT \\
\hline Potential BW records & 308,789 & 48,446 \\
BW not captured & 81,606 & 1,104 \\
Identical BW for $>5$ d & 23,543 & 0 \\
Virgin heifer induced into lactation & 10,202 & - \\
Unknown calving or lactation end date & 5,502 & 685 \\
Scale malfunction period & 2,735 & - \\
BW outlier & 944 & 104 \\
Milk yield outlier & 1,902 & 595 \\
Days in milk $>365$ & 5,860 & 3,827 \\
Missing sire identification & 16,478 & 0 \\
\hline
\end{tabular}

where $\boldsymbol{y}=$ vector of observations (any 4 of the following traits: daily $\mathrm{BW}$, daily MY, FY, PY, BCS, and DMI); $\beta=$ a vector of fixed effects for lactation nutritional trial at PSU, herd-date, age and age $^{2}$ within lactation 1,2 , or $\geq 3$, and 52 classes corresponding to week of lactation; $\boldsymbol{a}=$ a vector of random effects for animal; $\boldsymbol{p}=$ vector of random permanent environment effects; $\boldsymbol{e}=$ vector of residual effects; and $X, Z$, and $W$ are the incidence matrices. The animal effect assumes a single level for animal that is equivalent within and across lactations. The same assumption is made for the permanent environmental effect. All fixed effects were significant for BCS $(P<0.05)$ and highly significant $(P<0.001)$ for all other traits. Herd-date was replaced by herd-year-season for BCS, because the number of cows receiving a BCS on a given day was minimal. A 2-trait animal model for daily BW and MY was also analyzed for both herds individually. The pedigree file contained 1,705 animals, which included 650 cows with records from 149 sires, 484 dams, and 422 other ancestors. Twenty-one percent of VT cows had a PSU paternal half-sister, whereas only $5 \%$ of PSU cows had a paternal half-sister in VT, because data were available from a longer time period in PSU.

Body weight and changes in BW across lactation were analyzed with the following random regression model:

$$
\begin{gathered}
y_{i j k l m n q}=T_{j}+\operatorname{HDAT}_{k}+\sum_{a=1}^{2} b_{a l} \times a g e^{a}\left(L G_{l}\right) \\
+ \text { week }_{m}+\sum_{n=0}^{4} a_{i n} L+\sum_{q=0}^{6} p_{i q} L+e_{i j k l m n q}
\end{gathered}
$$

where $y=$ daily BW for cow $i$; $T$ = fixed effect of nutritional treatment $j ; H D A T=$ fixed effect of herd-date $k ; b_{a l}=$ regression on age at calving nested in lactation group 1 ; week = fixed effect for week of lactation $m$; $a=$ random regression coefficient for animal $i$ on a Legendre polynomial of DIM $(L)$ of order $\mathrm{n} ; p=$ random regression coefficient for the permanent environmental effect of cow $i$ on $L$ of order $q$; and $e=$ random residual. There were a total of 5 animal effects (intercept plus fourth-order polynomials for DIM) and 7 permanent environmental effects (intercept plus sixthorder polynomials for DIM). The model failed to converge when a greater order for DIM was attempted for both animal and permanent environment effects. However, reducing the number of animal or permanent environmental effects increased the Bayesian information criterion, so the best-fitting model was the greatest order that resulted in convergence. The animal and permanent environmental structures assume that variance changes within lactation but not across lactation. Dechow et al. (2004) fit multidimensional random regression sire models for BCS that fit both within and across lactation genetic variance. There was generally a single observation per cow for a single lactation in that analysis, which allowed the permanent environmental effect to be fit with only 3 variance components compared with 7 in the current study. Adding a linear random effect across lactation in the current study would have resulted in 21 and 36 covariance components for animal and permanent environment, respectively, which would have increased computing times and memory requirements considerably, so it was not attempted.

Genetic and permanent environmental (co)variance matrices for daily BW at DIM 0 to 305 in 5-d increments, change in BW from 0 to $30 \mathrm{DIM}$, and change

Table 2. Total number of observations (N) and mean and standard deviations for daily BW, milk yield (MY), BCS, DMI, fat yield (FY), and protein yield (PY)

\begin{tabular}{lrrrrrrr}
\hline & \multicolumn{3}{c}{ PSU } & & \multicolumn{3}{c}{ VT } \\
\cline { 2 - 4 } \cline { 6 - 7 } Trait & \multicolumn{1}{c}{$\mathrm{N}$} & Mean & SD & & $\mathrm{N}$ & Mean & SD \\
\hline BW (kg) & 160,017 & 654.9 & 92.4 & & 42,131 & 590.9 & 78.5 \\
MY (kg) & 249,115 & 37.1 & 11.2 & & 41,822 & 33.4 & 9.2 \\
BCS & 2,320 & 3.1 & 0.34 & & - & - & - \\
DMI (kg) & 8,624 & 17.3 & 6.50 & & - & - & - \\
FY (kg) & 5,386 & 1.5 & 0.53 & & - & - & - \\
PY (kg) & 5,386 & 1.2 & 0.30 & & - & - & \\
\hline
\end{tabular}


in BW from 0 to 100 DIM were estimated from model [2] using the procedures outlined by Jamrozik and Schaeffer (1997). To estimate heritability for BW change, genetic variance for $\mathrm{BW}$ change $\left(\sigma_{0-30}^{2}\right)$ was first estimated as:

$$
\sigma_{0-30}^{2}=\sigma_{0}^{2}+\sigma_{30}^{2}-2 \times \sigma_{0,30}
$$

where $\sigma_{0}^{2}=$ the genetic variance estimate on DIM 0; $\sigma_{30}^{2}=$ genetic variance on DIM 30; and $\sigma_{0,30}=$ genetic covariance between DIM 0 and 30. Phenotypic and permanent environmental variances were estimated using the same procedures. Variance estimates for BW change from 0 to 100 DIM were estimated likewise.

A comparison was made with a single residual structure to a model with 5 residual structures corresponding to the following months of lactations: 1,2 to 3,4 to 5,6 to 8 , and 9 to 12 . Two-trait models with genetic parameters for BW assumed to vary across lactation as in model [2] and genetic parameters for a second trait assumed to remain constant across lactation as in model [1] were used to estimate the relationship of BW across lactation with daily MY, PY, and BCS. Twotrait random regression models that included DMI and FY failed to converge.

\section{RESULTS}

The total number of observations with their mean and standard deviation for each of the 6 traits is presented in Table 2. Daily BW (202,148 total) and daily MY (290,937 total) had the most records, and BCS had the smallest number of observations $(2,320)$. The average daily BW was $654.9 \mathrm{~kg}$ for PSU and $590.9 \mathrm{~kg}$ for VT, whereas average daily MY was 37.1 and 33.7 $\mathrm{kg} / \mathrm{d}$ for PSU and VT, respectively. The average DMI from -28 to 0 DIM was $12.75 \mathrm{~kg}$, and DMI from 1 to 59 DIM was $19.86 \mathrm{~kg}$, with an overall average DMI of $17.3 \mathrm{~kg} / \mathrm{d}$. Body condition scores were available for 655 , 871, 568, and 226 lactations at calving, 30 DIM, first service, and dry-off, respectively. Mean BCS were 3.3 at calving, 3.0 at 30 DIM, 2.9 at first service, and 3.2 at dry-off.

Estimates of heritability, repeatability, genetic variance, and genetic and phenotypic correlations of daily BW and MY with BCS, DMI, fat, and PY are reported in Table 3. Heritability (0.46) and repeatability (0.76) estimates were greatest for daily BW. Repeatability estimates (0.37 to 0.48 ) were moderate for daily MY, FY, PY, BCS, and DMI, but heritability estimates were 0.14 or smaller for all except BCS (0.26). Body weight had a significant genetic correlation with BCS (0.60) and a significant phenotypic correlation with BCS
(0.43) and DMI (0.28). Genetically, daily MY was negatively correlated with daily $\mathrm{BW}(-0.14)$ and BCS $(-0.34)$, but the standard errors were relatively large and the correlations were not significantly different from zero.

Genetic parameter estimates for the individual analysis of PSU and VT herds are reported in Table 4 , whereas average BW curves for each herd are displayed in Figure 1. The cows from the VT herd weighed 40 to $80 \mathrm{~kg}$ less than PSU cows within their respective lactation group. However, heritability estimates for daily BW (0.87) and MY (0.53) were larger for VT than PSU (0.40 and 0.10, respectively). The genetic correlations between daily BW and MY were moderately positive for the VT herd (0.31) but moderately negative for the PSU herd (-0.32).

Correlations of EBV for daily BW and MY with official August 2007 national genetic evaluations for MY and selected type traits (retrieved from http:// www.dairybulls.com) are reported in Table 5 for the PSU and VT herds. Estimated breeding values were obtained from the single-herd analyses. Correlations for the PSU herd were based on 20 bulls that had a reliability for daily MY of at least 0.35 , whereas correlations for VT were based on 23 bulls with reliability for daily MY of 0.35 or more. The 20 bulls from PSU sired 284 cows (54\% of total), whereas the $23 \mathrm{VT}$ bulls sired 96 cows ( $80 \%$ of herd total). Correlations between EBV for daily BW and standardized transmitting ability (STA) for size-related traits in the PSU herd were significant, ranging from 0.42 to 0.76 , whereas correlations of EBV for daily BW from the VT herd and STA for type traits were not significant. In contrast to the genetic correlation obtained for the VT herd between daily BW and daily MY, the correlation between EBV for daily MY and STA for body size composite was -0.44 for the VT herd. Estimated breeding values for daily MY from both herds were significantly correlated with official PTA for MY despite relatively low reliability for daily MY EBV.

The heritability and genetic variance estimates for daily BW across the lactation derived from random regression models with single and multiple residual structures are represented in Figure 2. The trend of heritability and genetic variance estimates was very similar with single and multiple residual structures. Body weight was highly heritable with heritability estimates as large as 0.57 . The choice of residual structures had minimal influence on genetic variance estimates. The genetic variance estimate declined during the early part of lactation until approximately 40 DIM and then increased until the end of lactation. Genetic correlations of daily BW at 0,100 , and 300 DIM with BW at all other DIM are reported in Figure 3. In gen- 
Table 3. Estimates of heritability $\left(h^{2}\right)$, repeatability $(\mathrm{R})$, additive genetic standard deviation $\left(\mathrm{SD}_{\mathrm{a}}\right)$, genetic $\left(r_{g}\right)$ and phenotypic $\left(r_{p}\right)$ correlations of daily BW and milk yield (MY) with fat yield (FY), protein yield (PY), $\mathrm{BCS}$, and DMI with their respective standard errors

\begin{tabular}{|c|c|c|c|c|c|c|c|}
\hline \multirow[b]{2}{*}{ Trait } & \multirow[b]{2}{*}{$\mathrm{h}^{2}$} & \multirow[b]{2}{*}{$\mathrm{R}$} & \multirow[b]{2}{*}{$\mathrm{SD}_{\mathrm{a}}$} & \multicolumn{2}{|c|}{$r_{g}$} & \multicolumn{2}{|c|}{$\mathrm{r}_{\mathrm{p}}$} \\
\hline & & & & BW & MY & BW & MY \\
\hline BW & $0.46 \pm 0.06$ & $0.76 \pm 0.01$ & 43.02 & 1.00 & $-0.14 \pm 0.18$ & 1.00 & $-0.02 \pm 0.02$ \\
\hline MY & $0.14 \pm 0.04$ & $0.48 \pm 0.01$ & 3.79 & $-0.14 \pm 0.18$ & 1.00 & $-0.02 \pm 0.02$ & 1.00 \\
\hline FY & $0.04 \pm 0.02$ & $0.37 \pm 0.01$ & 0.11 & $0.11 \pm 0.24$ & $0.65 \pm 0.15$ & $0.00 \pm 0.02$ & $0.80 \pm 0.01$ \\
\hline PY & $0.14 \pm 0.03$ & $0.45 \pm 0.01$ & 0.11 & $-0.07 \pm 0.16$ & $0.85 \pm 0.04$ & $0.02 \pm 0.02$ & $0.95 \pm 0.00$ \\
\hline $\mathrm{BCS}$ & $0.26 \pm 0.06$ & $0.40 \pm 0.03$ & 0.14 & $0.60 \pm 0.11$ & $-0.34 \pm 0.20$ & $0.43 \pm 0.02$ & $-0.18 \pm 0.02$ \\
\hline DMI & $0.07 \pm 0.14$ & $0.46 \pm 0.03$ & 0.77 & $0.51 \pm 0.78$ & $1.01 \pm 1.30$ & $0.28 \pm 0.04$ & $0.40 \pm 0.03$ \\
\hline
\end{tabular}

eral, the genetic correlations were large across lactation but comparatively smaller between early and midlactation. The smallest genetic correlation (0.72) was observed between 0 and 100 DIM. The heritability estimate for daily BW change from 0 to $30 \mathrm{~d}$ was 0.16 , whereas the heritability estimate for daily BW change from 0 to $100 \mathrm{~d}$ was 0.31 .

Genetic correlations of BCS, PY, and daily MY with BW across the lactation are reported in Figure 4. The genetic correlation of BCS with BW declined until 100 DIM and then increased. Genetic correlations of daily BW with daily MY and PY tended to be less negatively correlated with BW when the genetic correlation of BW and BCS was smallest.

\section{DISCUSSION}

The heritability estimate of daily BW from the 4trait model was 0.46 , and heritability estimates from random regression range from 0.50 to 0.57 , which is within the range of other studies (Veerkamp and Brotherstone, 1997; Berry et al., 2002). The choice of number of residual variance structures had minimal influence on genetic variance or heritability estimates. Differences in residual variance were largely offset by changes in the permanent environmental variance, which is similar to the observations of Dechow et al. (2004) for BCS and dairy form. The heritability estimate of BCS in the present study is 0.26 , which was well within the range of many studies (Jones et al., 1999; Koenen et al., 2001; Berry et al., 2002), but was

Table 4. Comparison of heritability and repeatability estimates for daily BW and milk yield (MY) in the Pennsylvania State University (PSU) and Virginia Tech (VT) dairy herds

\begin{tabular}{lrc}
\hline Parameter & PSU & VT \\
\hline Heritability of BW & $0.40 \pm 0.07$ & $0.87 \pm 0.01$ \\
Repeatability of BW & $0.73 \pm 0.01$ & $0.87 \pm 0.01$ \\
Heritability of MY & $0.10 \pm 0.04$ & $0.53 \pm 0.12$ \\
Repeatability of MY & $0.49 \pm 0.01$ & $0.57 \pm 0.03$ \\
Genetic correlation (BW and MY) & $-0.32 \pm 0.19$ & $0.31 \pm 0.09$ \\
\hline
\end{tabular}

lower than 0.58 reported by Berry et al. (2003). The ability to automate BW measurements coupled with the high heritability of BW make automated weighing systems an attractive tool to provide an indicator of energy balance change across lactation. Change in BCS is a more direct indicator of energy balance change than $\mathrm{BW}$ but is more labor-intensive at this time due to the lack of automation, and scoring is subjective. A combination of daily BW with BCS at defined lactation stages, such as calving and first insemination, would provide accurate measures of energy balance change across lactation.

The heritability estimate for daily MY appears small when compared with heritability estimates for lactation total yields. However, the estimate is in close agreement with the estimate $(0.10)$ obtained by Sawalha et al. (2005) when a repeatability model was applied to test-day records. Reliability is still expected to be relatively large, because there are many observations per lactation. Random regression models that allow genetic variance estimates to vary across lactation may have also resulted in larger heritability estimates but were not attempted, because MY was not the primary focus of the current study. The heritability estimate for DMI (0.07) was much smaller than the estimate of 0.61 reported by Veerkamp et al. (2000).

Table 5. Correlations of EBV for daily BW and milk yield (MY) for 20 bulls with daughters in the Pennsylvania State University (PSU) or 23 bulls with daughters in the Virginia Tech (VT) dairy herds with official PTA for MY and standardized transmitting ability for selected linear type traits

\begin{tabular}{|c|c|c|c|c|}
\hline \multirow[b]{2}{*}{ Item } & \multicolumn{2}{|c|}{ PSU } & \multicolumn{2}{|c|}{ VT } \\
\hline & MY & BW & MY & BW \\
\hline PTA milk & $0.44 \dagger$ & -0.33 & 0.49 ** & -0.22 \\
\hline Body size composite & -0.18 & $0.67 * *$ & $-0.44^{*}$ & 0.18 \\
\hline Stature & -0.02 & $0.42 \dagger$ & -0.26 & 0.16 \\
\hline Strength & -0.31 & $0.76^{* * *}$ & $-0.54 * *$ & 0.20 \\
\hline Body depth & -0.24 & $0.76^{* * *}$ & $-0.56^{* *}$ & 0.21 \\
\hline Thurl width & -0.27 & $0.46^{*}$ & -0.15 & -0.06 \\
\hline Dairy form & 0.18 & -0.15 & 0.19 & -0.13 \\
\hline
\end{tabular}




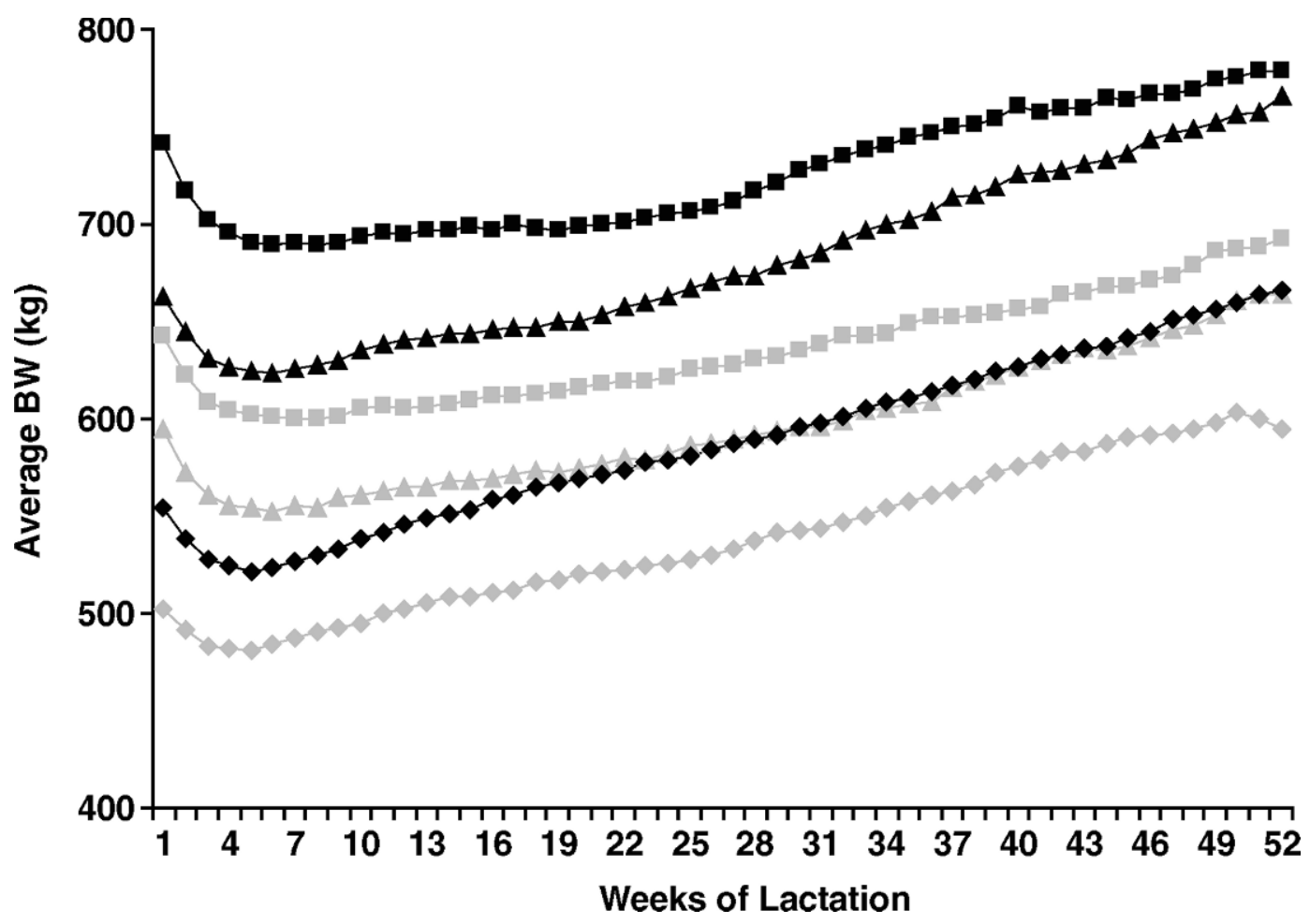

Figure 1. Comparison of average BW curves for first ( ), second ( $\mathbf{\Delta}$ ), and third (ם) lactations, respectively, in the Virginia Tech (gray lines) and the Pennsylvania State University (black lines) dairy herds.

The data included both pre- and postpartum DMI, and DMI may be under significantly different genetic regulation before and after calving. Attempts to analyze
DMI separately from each period did not result in larger heritability estimates. The effect of nutritional trial during the current lactation was included as a

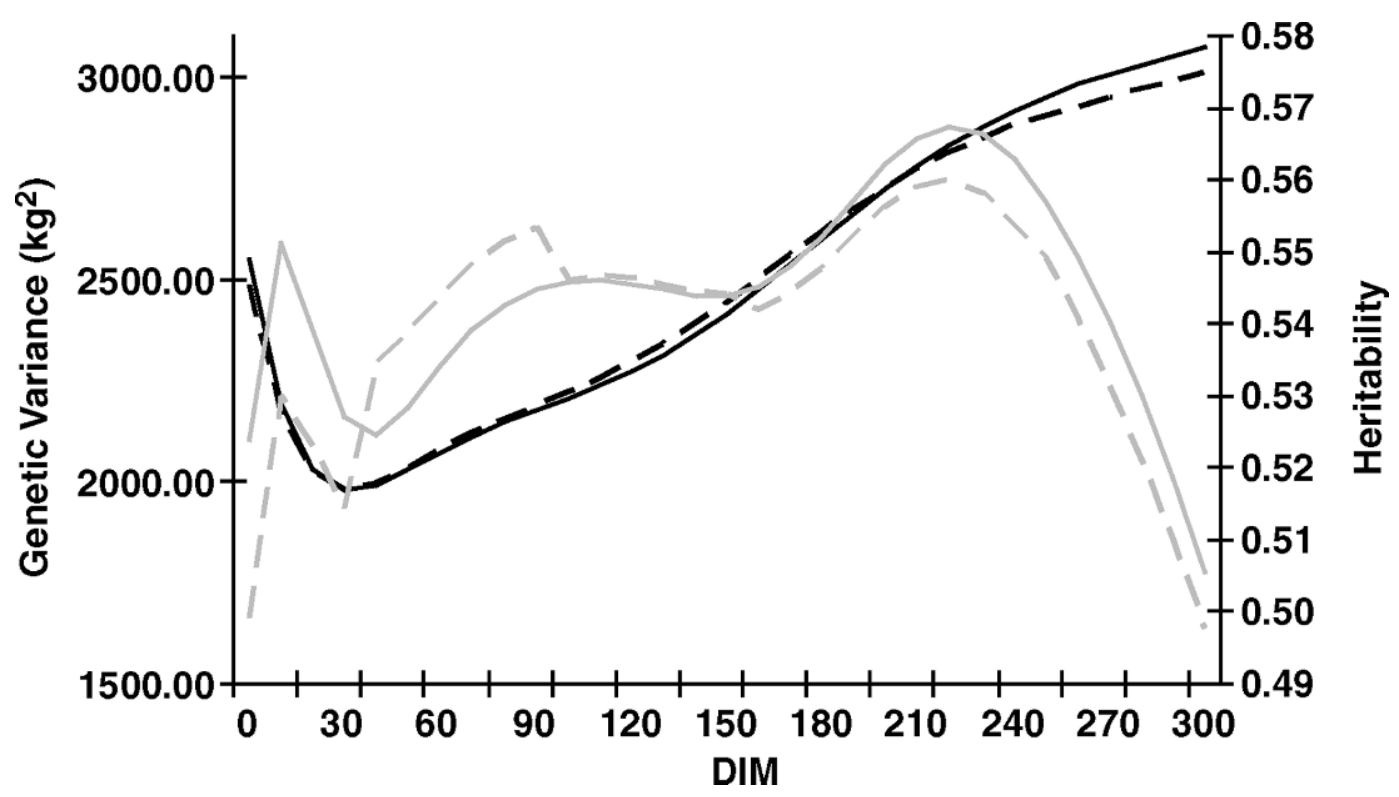

Figure 2. Heritability (gray lines) and genetic variance (black lines) estimates of daily BW across lactation with models that assume single (solid lines) and multiple (dashed lines) residual structures. 


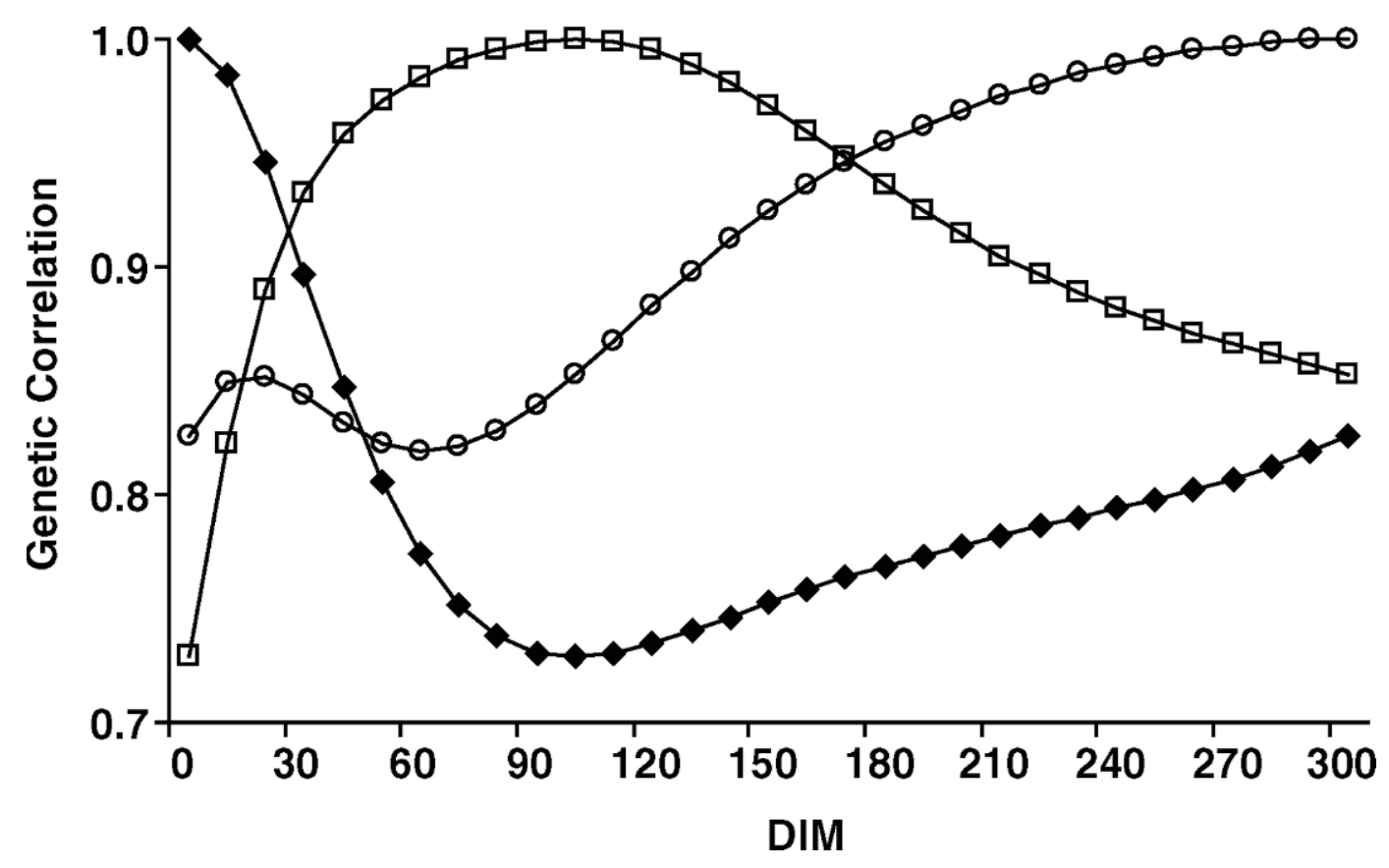

Figure 3. Genetic correlations of BW at $0(\diamond), 100(\square)$, and 300 DIM $(\bigcirc)$ with BW across lactation.

fixed effect. Nesting nutritional trial within herd-date and week of lactation was also considered but did not increase heritability estimates. Many of the cows in these herds have been part of multiple nutritional trials. It is possible that the cumulative influence of nutrition trials over the lifespan of a cow masked genetic potential for MY and DMI, resulting in depressed heritability estimates.

The relationship between BW and MY is complicated, because BW is dependent on both the frame size of a cow and BCS. If variation in BW was determined by frame size alone, greater BW would likely be associated with more MY because of the correlation between BW and DMI. Dry matter intake, in turn, has a positive genetic correlation with MY. The association between frame size and MY can be demonstrated by adjusting the correlation between BW and MY for BCS. Veerkamp and Brotherstone (1997) reported a slightly negative correlation between MY and live weight $(-0.09)$ but a moderate positive correlation (0.29) between yield and live weight adjusted for BCS. The estimates in the present study are similar. The genetic correlation was -0.14 , but the partial correlation after adjusting for BCS was 0.24.

Van Elzakker and van Arendonk (1993) reported that the genetic correlation between yield and live weight changed from 0.29 in lactation wk 3 to -0.25 in wk 13, and Veerkamp and Brotherstone (1997) found that the genetic correlations between MY and $\mathrm{BW}$ measured at first calving or as an average during lactation were positive and negative, respectively. The change in genetic correlation between MY and BW at different lactation stages reflects that stored body fat is an important contributor to BW during some parts of lactation, and body tissue mobilization is related to MY. The genetic correlation between daily BW and BCS in this study was 0.60 , which was greater than the 0.48 estimate reported by Madgwick et al. (1991) and within the range (0.27 to 0.67$)$ reported by Veerkamp and Brotherstone (1997). Figure 4 also indicates a tendency for BCS to be more highly correlated with daily BW in early and late lactation than with daily BW in midlactation. The genetic correlations between daily BW and BCS observed in this study followed a trend similar to those reported by Berry et al. (2002), but the magnitude of genetic correlations were different. They reported the smallest genetic correlation of 0.35 at 120 DIM, compared with a correlation of 0.63 at 70 DIM in this study. It appears that variation in daily BW in early and late lactation is determined more by the degree of fatness than by the frame size, which plays a larger role in midlactation. The reduced influence of BCS on BW in midlactation is associated with an increase in genetic correlations of BW with MY and PY (Figure 4). The interactions among BW, MY, and BCS demonstrate the limitations of analyzing BW when BCS is not available. It is not apparent from BW alone whether a cow has a large frame size or has high body condition. 


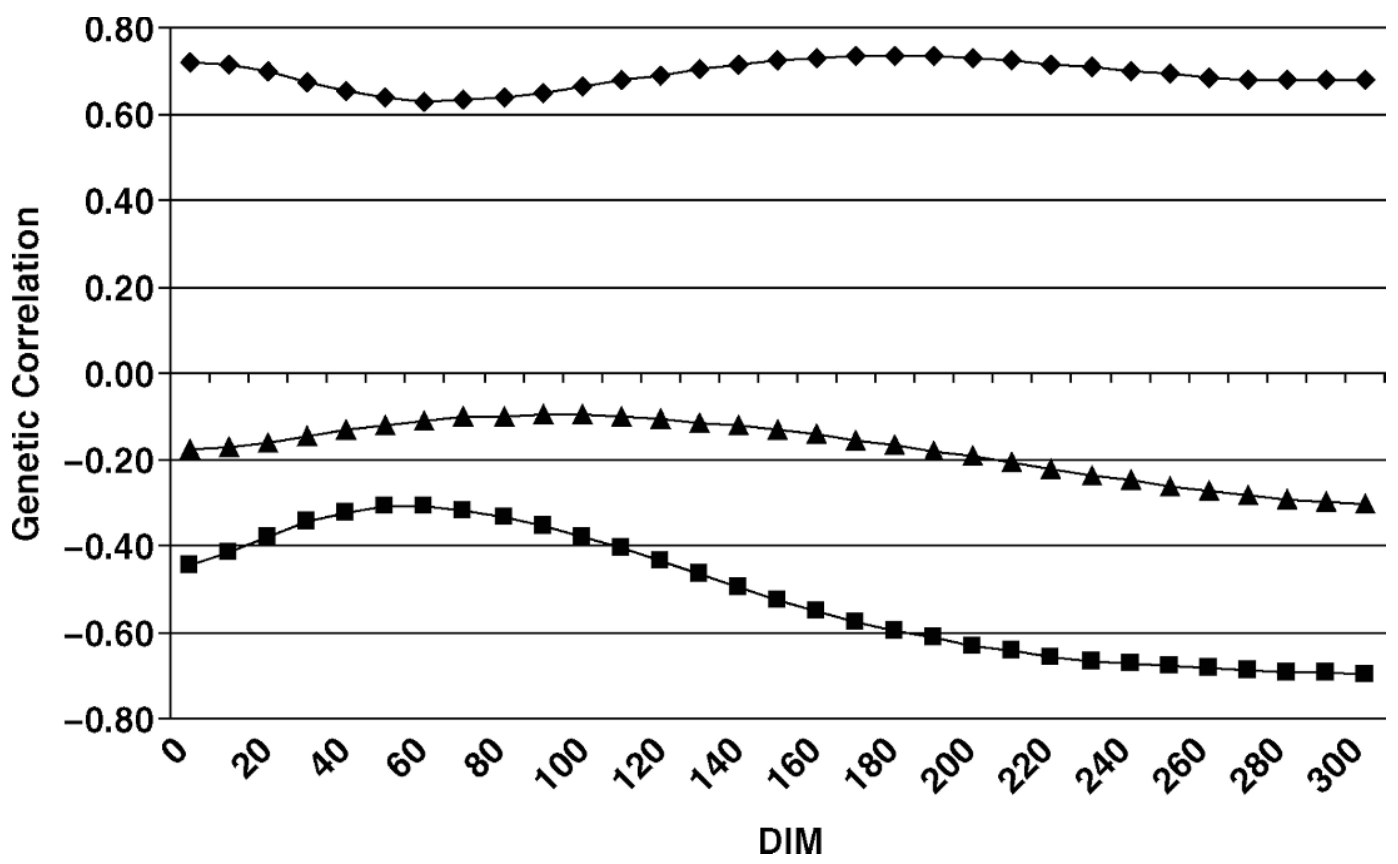

Figure 4. Genetic correlations of BCS $(\diamond)$, milk yield $(\boldsymbol{\Delta})$, and protein yield ( $\mathbf{\square})$ with BW across the lactation.

The mean daily BW of cows from PSU was greater than the mean daily BW of cows from VT. However, heritability estimates for daily BW and MY were larger for VT, and genetic correlations between daily BW and MY were the opposite in direction when compared with PSU. The larger daily BW might indicate that cows at PSU had more body condition than cows at VT and that the genetic correlation between daily BW and MY at PSU was influenced more strongly by differences in BCS when compared with VT. The scales at the respective universities have not been cross-validated to ensure that they measure identically across herds, and it is possible that the greater daily BW at PSU reflects differences in scale calibration. However, the scales are calibrated regularly at both institutions, and it is unlikely that there are large measurement differences across herds. Invalid daily BW observations and scale errors were more frequent at PSU (Table 1), which could indicate greater error rates at PSU and, subsequently, depressed heritability estimates. The repeatability estimates between the herds were not as different, however. Thus, the differences in heritability estimates between the 2 herds may simply reflect sampling error due to observations from a relatively small number of cows in the VT herd.

An additional complication between BW and MY is that cows with large frames have more total body fat than smaller-framed cows with equal BCS, which may explain some of the differences observed in PSU and VT. Banos et al. (2006) reported methods to estimate body lipid and protein content using BW and BCS observations. Those formulas were applied to second lactation PSU and VT cows at wk 10 and 44 after calving to demonstrate the additional energy required by PSU cows to accumulate body tissue. Cows from both herds were assumed to have BCS of 2.81 at wk 10 and 3.45 at wk 44 , which are the values reported by Dechow et al. (2002) for BCS at first insemination and dry-off and represent typical BCS for those lactation stages in the United States. Conception was assumed to have occurred at 110 DIM for both herds. The PSU cows weighed $635 \mathrm{~kg}$ at wk 10 and $733 \mathrm{~kg}$ at wk 44, whereas the VT cows weighed 561 and 637 $\mathrm{kg}$ at wk 10 and 44, respectively (Figure 1 ). The PSU cows were estimated to have $90.2 \mathrm{~kg}$ of body lipid at wk 10 and $130.0 \mathrm{~kg}$ of body lipid at wk 44, representing a 38.8-kg accumulation of body lipid. The PSU cows also gained $5.6 \mathrm{~kg}$ of body protein. The VT cows were estimated to have gained 31.9 and $3.2 \mathrm{~kg}$ of body lipid and protein, respectively, from wk 10 to 44 . The total energy required to support weight gain was $2,452 \mathrm{MJ}$ for PSU cows and 1,945 MJ for VT cows, even though cows from both herds were assumed to have identical BCS. If the difference in BW between PSU and VT is assumed to reflect consistently greater BCS for PSU cows, the difference in energy is even greater. For example, if PSU cows have a BCS of 2.91 at first service and 3.55 at dry-off ( 0.1 greater than VT), then 2,474 MJ are required. The additional body energy accumulated by PSU cows may partly account for the differ- 
ence in the genetic correlation between BW and MY observed between herds.

Figure 3 indicates that daily BW in early and midlactation are under somewhat different genetic control and that there are genetic differences among cows for the amount of daily BW change in the first 100 DIM. The heritability estimates for BW change indicate that reasonably accurate genetic evaluations for BW change could be generated if automated daily $\mathrm{BW}$ were available from progeny test herds. Dechow et al. (2002) reported that selection for MY resulted in more body fat mobilization in early lactation. However, the genetic correlation between BW loss between 0 and 100 DIM and daily MY was not strong (-0.11) in this study. This indicates that opportunities exist to select for greater MY while minimizing early lactation BW loss.

The correlations presented in Table 5 between EBV for daily BW from PSU and official STA for size-related traits were strong, especially when one considers that the daily BW EBV reflect data from a limited number of daughters. Body weight EBV were not as strongly correlated with size-related traits in the VT herd. Although the genetic correlation between daily BW and MY was positive in the VT herd, correlations of EBV for daily MY with STA for body size composite were negative, which is in agreement with genetic correlations estimated for the PSU herd. This may reflect sampling error, or indicate that daily $\mathrm{BW}$ is under somewhat different genetic control in VT than in PSU. Reasons for widely different parameter estimates between PSU and VT are not clear, but they do indicate that correlations among daily BW and other traits (such as MY) could vary among herds.

\section{CONCLUSIONS}

Body weight is a highly heritable trait, and automated body-weighing systems could be installed in progeny test herds to estimate daughter BW curves with a high degree of accuracy. Body weight is a complex trait that is influenced by both frame size and BCS, so BW observations should be supplemented with BCS and linear-type appraisals to describe the body composition of daughters. Daily BW combined with BCS at specific lactation stages, such as calving and first insemination, could provide accurate assessments of energy balance change across lactation. The relationship between yield and BW is complex and is largely influenced by BCS. However, potential exists to select animals with less BW loss at high levels of milk production, which is expected to improve cow health and reproductive performance.

\section{REFERENCES}

Banos, G., M. P. Coffey, E. Wall, and S. Brotherstone. 2006. Genetic relationship between first-lactation body energy and later-life udder health in dairy cattle. J. Dairy Sci. 89:2222-2232.

Berry, D. P., F. Buckley, P. Dillon, R. D. Evans, M. Rath, and R. F. Veerkamp. 2002. Genetic parameters for level and change of body condition score and body weight in dairy cows. J. Dairy Sci. 85:2030-2039.

Berry, D. P., F. Buckley, P. Dillon, R. D. Evans, M. Rath, and R. F. Veerkamp. 2003. Genetic relationships among body condition scores, body weight, milk yield, and fertility in dairy cows. J. Dairy Sci. 86:2193-2204.

Butler, W. R., R. W. Everett, and C. E. Coppock. 1981. The relationships between energy balance, milk production and ovulation in postpartum Holstein cows. J. Anim. Sci. 53:742-748.

Butler, W. R., and R. D. Smith. 1989. Interrelationships between energy balance and postpartum reproductive function in dairy cattle. J. Dairy Sci. 72:767-783.

Chung, Y. H., T. W. Cassidy, I. D. Girard, P. Cavassini, and G. A. Varga. 2005. Effects of rumen protected choline and dry propylene glycol on feed intake and blood metabolites of Holstein dairy cows. J. Dairy Sci. 88(Suppl. 1):61. (Abstr.)

Coffey, M. P., G. C. Emmans, and S. Brotherstone. 2001. Genetic evaluations of dairy bulls for energy balance traits using random regression. Anim. Sci. 73:29-40.

Coffey, M. P., G. Simm, W. G. Hill, and S. Brotherstone. 2003. Genetic evaluations of dairy bulls for daughter energy balance profiles using linear type scores and body condition score analyzed using random regression. J. Dairy Sci. 86:2205-2212.

Dechow, C. D., G. W. Rogers, and J. S. Clay. 2002. Heritability and correlations among body condition score loss, body condition score, production and reproductive performance. J. Dairy Sci. 85:3062-3070.

Dechow, C. D., G. W. Rogers, L. Klei, and T. J. Lawlor. 2004. Heritability and correlations for body condition score and dairy form within and across lactation and age. J. Dairy Sci. 87:717-728.

Gilmour, A. R., B. J. Gogel, B. R. Cullis, S. J. Welham, and R. Thompson. 2006. AS-REML User Guide. Release 1.0. VSN International Ltd., Hemel Hempstead, UK.

Jamrozik, J., and L. R. Schaeffer. 1997. Estimates of genetic parameters for a test day model with random regressions for yield traits of first lactation Holsteins. J. Dairy Sci. 80:762-770.

Jensen, J., W. D. Hohenboken, P. Madsen, and B. B. Andersen. 1995. Sire $\times$ nutrition interaction and genetic parameters for energy intake, production and efficiency of nutrient utilization in young bulls, heifers, and lactating cows. Acta Agric. Scand. A. Anim. Sci. 45:81-91.

Jones, H. E., I. M. S. White, and S. Brotherstone. 1999. Genetic evaluation of Holstein-Friesian sires for daughter conditionscore changes using a random regression model. Anim. Sci. 68:467-475.

Karcher, E. L., M. M. Pickett, G. A. Varga, and S. S. Donkin. 2007. Effect of dietary carbohydrate and monensin on expression of gluconeogenic enzymes in liver of transition dairy cows. J. Anim. Sci. 85:690-699.

Kensinger, R. S., A. L. Magliaro, R. Graboski, P. R. Tozer, M. L. O'Connor, and L. D. Muller. 2005. Induced lactation in 15 month old heifers: Production, health and survival. J. Dairy Sci. 88(Suppl. 1):364. (Abstr.)

Koenen, E. P. C., and A. F. Groen. 1998. Genetic evaluations of body weight of lactating Holstein heifers using body measurements and conformation traits. J. Dairy Sci. 81:1709-1713.

Koenen, E. P. C., R. F. Veerkamp, P. Dobbelaar, and G. De Jong. 2001. Genetic analysis of body condition score of lactating Dutch Holstein and Red-and-White heifers. J. Dairy Sci. 84:1265-1270.

Lassen, J., M. Hansen, M. K. Sorensen, G. P. Aamand, L. G. Christensen, and P. Madsen. 2003. Genetic relationship between body condition score, dairy character, mastitis, and diseases other than mastitis in first-parity Danish Holstein cows. J. Dairy Sci. 86:3730-3735. 
Lee, A. J., D. A. Boichard, A. J. McAllister, C. Y. Lin, K. Nadarajah, T. R. Batraa, G. L. Roy, and J. A. Vesely. 1992. Genetics of growth, feed intake, and milk yield in Holstein cattle. J. Dairy Sci. 75:3145-3154

Madgwick, P. P., K. A. Beard, and M. E. Goddard. 1991. Possibilities for incorporating selection for feed conversion efficiency into the national dairy herd improvement program. Pages 45-48 in Proc. 9th Mtg. Assoc. Adv. Anim. Breed. Gen. Aust. http://www. aaabg.org/AAABGproceedings.php Accessed June 26, 2008.

Maltz, E. 1997. The body weight of the dairy cow: III. Use for on-line management of individual cows. Livest. Prod. Sci. 48:187-200.

Ordway, R. S., V. A. Ishler, and G. A. Varga. 2002. Effects of sucrose supplementation on dry matter intake, milk yield, and blood metabolites of periparturient Holstein dairy cows. J. Dairy Sci. 85:879-888.

Peiper, U. M., Y. Edan, S. Devir, M. Barak, and E. Maltz. 1993. Automatic weighing of dairy cows. J. Agric. Eng. Res. 56:13-24.

SAS Institute. 2000. SAS/STAT User's Guide. Version 8. SAS Inst. Inc., Cary, NC.
Sawalha, R. M., J. F. Keown, S. D. Kachman, and L. D. Van Vleck. 2005. Evaluation of autoregressive covariance structures for test-day records of Holstein cows: Estimates of parameters. J. Dairy Sci. 88:2632-2642.

Svendsen, M., P. Skipenes, and I. L. Mao. 1994. Genetic correlations in the feed conversion complex of primiparous cows at a recommended and a reduced plane of nutrition. J. Anim. Sci. 72:1441-1449.

van Elzakker, P. J. M., and J. A. M. van Arendonk. 1993. Feed intake, body weight and milk production: Genetic analysis of different measurements in lactating dairy heifers. Livest. Prod. Sci. 37:37-51.

Veerkamp, R. F., and S. Brotherstone. 1997. Genetic correlations between linear type traits, food intake, live weight, and condition score in Holstein-Friesian dairy cattle. Anim. Sci. 64:385-392.

Veerkamp, R. F., J. K. Oldenbroek, H. J. Van Der Gaast, and J. H. J. Van Der Werf. 2000. Genetic correlation between days until start of luteal activity and milk yield, energy balance, and live weights. J. Dairy Sci. 83:577-583. 